\title{
Linguistic Variations and Use of the 21st Century Arabicisation of English
}

\author{
Nuha Suleiman Al-Shurafa \\ King Abdul-Aziz University, Jeddah, Saudi Arabia
}

\begin{abstract}
This paper presents an account of linguistic variations which, by nature, deals with sociolinguistic perspectives of Arabicised-English. The study is directly devoted to the analysis of Arabicised-English and goes in line with the $\mathrm{x}$-isation theory. The major claim of this paper is that this English variety as used by professional educated Arabs with good command of English manifests syntactic features that relates to the main structural constraint found in Arabic language and culturenglish. The Arabs' diglossic situation enables them to command "the hyperstyle variables" and to have a full access to the UG (Universal Grammar) rules. The theoretical framework as developed by Chomsky and the linguists following his line is able to capture generalizations presented in this paper which can be briefed in the following points: (1) The grammars of Arabicised-English are bound by grammatical constraints found in both English and Arabic; (2) Arabicisation of English is as systematic and logical as Standard English; and (3) The difference between the variety of the Arabicised-English and the Standard English is functional that is directly reflected by the Sociolinguistic Cultural Constraints other than the Theoretical Syntactic ones.
\end{abstract}

Keywords: Arabicised-English, x-isation theory, syntactic features, structural constraint, UG (Universal Grammar), diglossic situation, hyperstyle variables, culturenglish

\section{Introduction}

This study focuses on the linguistic features that distinguish Arabicised-English within the $\mathrm{x}$-isation theory. The study by nature deals with the globalization of English as well as the sociolinguistic perspectives. These points are subsequently discussed in the subsections below.

\section{The X-Isation Theory/Definition}

The $\mathrm{x}$-isation theory has recently been documented with reference to certain languages in the world (Stockwell, 2002; Fishman, Tabourel-Keller, Clyne, Krishnamurti, \& Abdulaziz, 1986; Maurice \& Morris, 2004; Hickey, 2004). It deals with the linguistic distinctiveness and realizations of such identities of English. It involves by nature globalization of English and the Englishes' variations which are best to consider within the $\mathrm{x}$-isation theory.

The term “Arabicised-English” discussed through this paper can be defined from the author's perspectives as: "The variety of English used by professional Arabs who have a good command of English. Such variety manifests syntactic features that relate to the main structural constraint found in Arabic language and culture”.

Even though Arabicisation has not been formally documented, the term and its implications as discussed

Nuha Suleiman Al-Shurafa, Ph.D., Department of European Languages, King Abdul-Aziz University. 
in this paper goes in line with "Indianisation”, “Africanisation”, and “Americanisation” of English. These have been documented for many years. Bhatt’s 2006, Warsi’s 2004, and Kachru’s 1988 are among many formal studies where Indianised-English have been identified and analyzed. Alim's 2004 is a recent contribution which studies a specific variety of American English, and Green's 2002 discusses the African-American English.

For example, Americanised-English has been documented since the 18th Century (Stockwell, 2002, p. 12) involving variant pronunciations such as "Rhoticity". Structural variants have also been document, such as verb forms variants like: "Do you got" and so on. However, Some of the Indianised-English include the "subject-object-verb word order” as: "I door open” (Stockwell, 2002, p. 21). These features are exhibited mainly at the verbal level.

\section{Global and Worlds Englishes}

World Englishes develop from English, and "a single, political answer" could be given to the question, "why World Englishes?”, "by pointing to the growth of the British Empire” (Crystal, 2004, p. 11). World Englishes are used as "neutral forms as in India” (Stockwell, 2002, p. 18; see also Melchers, 2003). Other international languages have included French, Spanish, Chinese, and even "Arabic across the Middle East, North Africa and other Islamic countries” (Stockwell, 2002, p. 18). Moreover, other languages' Englishes have been documented such as Maltese-English (Mazzon, 1993), Canadian (Lilles, 2000), Bulcan-Surbo (Greenberg, 2002), and Singapore (Crewe, 1977) Englishes.

English itself is a hybrid of many languages along the time. Figure 1 is a visual description of the origin and development of English language:

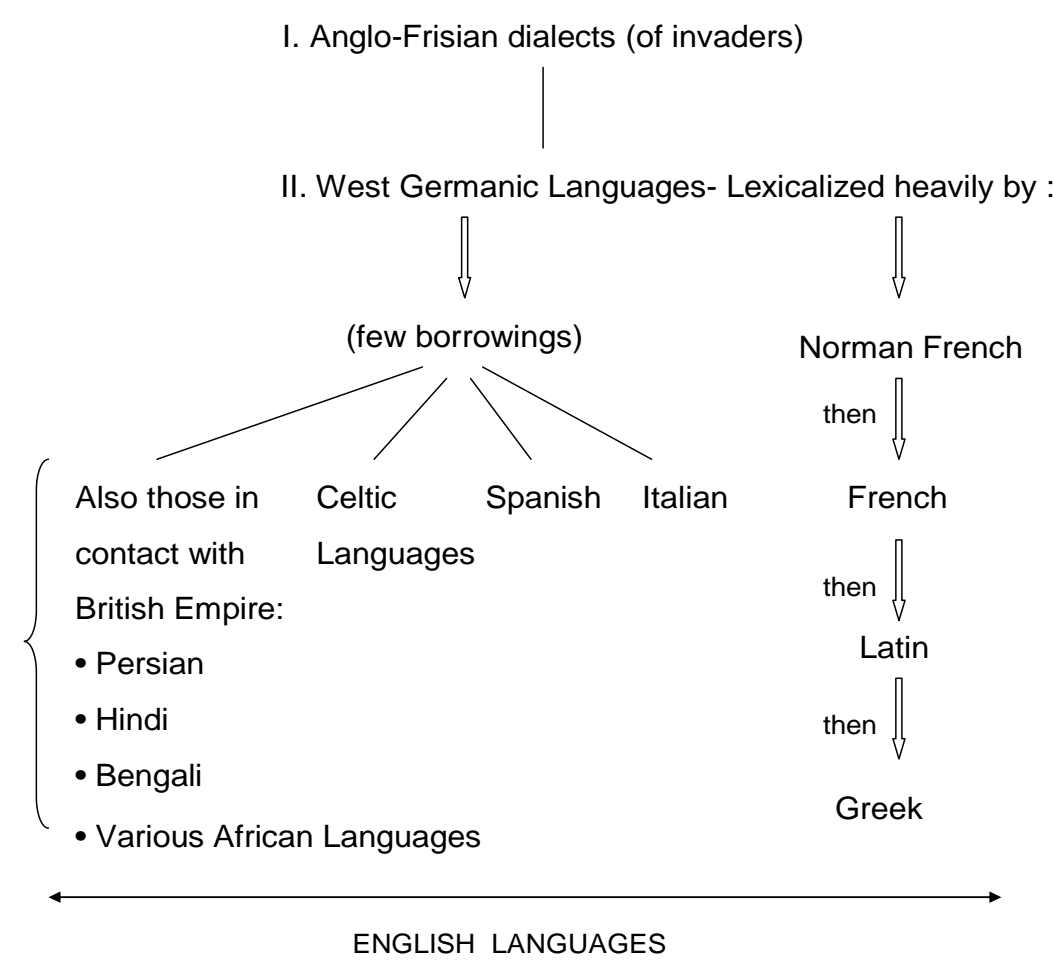

Figure 1. Greatly hybridised global English. Source: Adapted from Stockwell (2002, p. 17).

Figure 1 is a brief manifestation to emphasize that "English globalization is achieved by allowing itself to become greatly hybrid" (Stockwell, 2002, p. 17). 


\section{The Status of English in the Arab World}

It has become obvious in the 21st Century, and even few decades earlier, that English has enormously developed a special status in the Arab World and within families. The distinctive situation has ridden on the back of the world's economic and political influence. It provides the Arabs and the other World's nations, as a main reason, with a linguistic access to the Western World, among many other reasons. "Most telling, 80 percent of the global internet traffic is English” (Stockwell, 2002, p. 18).

\section{Sociolinguistic Perspectives and Statistics}

Each of the countries of the Arab World has changed dramatically over the past decades (Walters, 1996, p. 166). This change has clearly meant not only the end of literacy, but also the keenness of most families to make their children command another language of which English may come as first choice.

Figures 2-4 are visual inference in support of the above statement (these figures are adapted from the study by Kachru, 1988):

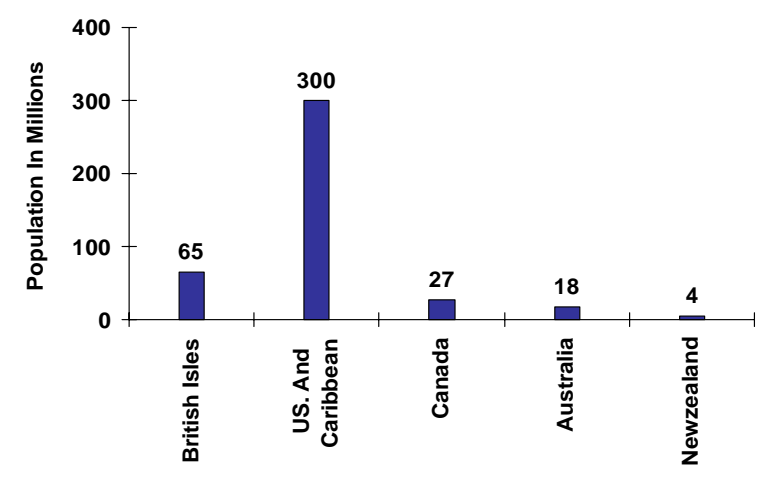

Figure 2. Regions of the world where English is the L1 (first language).

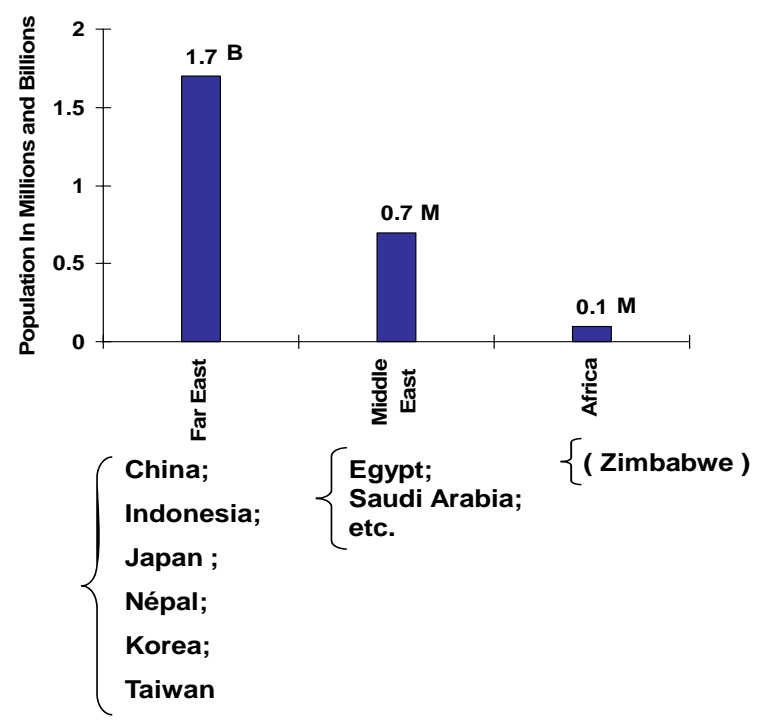

Figure 3. Regions of the world where English is the L2 (second language). 


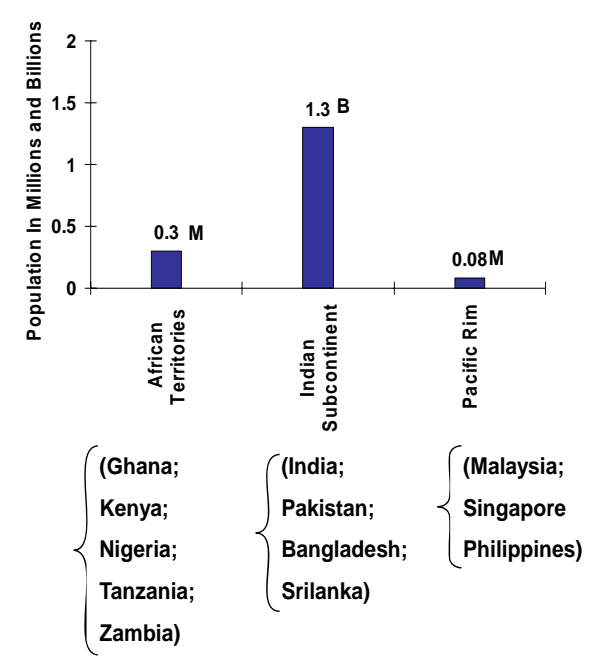

Figure 4. Regions of the world where English is of special importance.

The statistics in Figures 2-4 by Kachru (1988) are quite useful to our study though achieved about three decades ago. They reveal that English language status in the wide world (see Figure 2 and Figure 4) as well as in the Middle East (see Figure 3).

Standard English (see Greenbaum \& Quirk, 2000; Quirk, 2003) is found in countries where English is L1 and is used as the main or the dominant language (see Figure 2). Twenty percent of the world population uses English as L1 and L2 (see Figures 2-3), whereas 45\% (as in Figure 4: more than 1.5 billion) of the world's total population consider English with special importance-though not everyone speaks it (Stockwell, 2002, pp. 20-21).

Sociolinguistically, English is admired by the Arabs and is highly desirable to be taught to children and to be spoken among the educated individuals. It is a sociolinguistic context that exists in many communities (see Figure 4) and has been acknowledged by other scholars (Raley, 1999; Crystal, 2003; Crewe, 1977; Foley, 1988; Mazzon, 1993; Lilles, 2000; Trudgill, 1999; Wright, 2004).

\section{Theoretical Framework and Questions}

English and Arabic are two Languages which differ grammatically. The difference becomes obvious with the complex structure particularly with respect to relative clauses formation. English has a strong overt syntactic movement (at the surface structure) and Arabic has a weak movement of the pronoun at the LF (Logical Form) level (Bolotin, 1996, p. 138; Demirdache, 1991). Simple and complex clauses are among other structural variations this paper discusses. However, the simple and complex clauses involve a set of parameters where settings are determined by the one particular language.

The core set of UG (Universal Grammar) properties (Chomsky, 1995) is useful here to consider. The generative framework relates to UG properties and is best to apply in order to examine: (1) Arabicised-English positive reaction towards resetting parameters in simple and complex clauses; (2) UG properties which are fully accessed by Arabs in the Arabicised-English as a positive reaction of the sociolinguistic-diglossic situation found in their own language; (3) other linguistic varieties are inserted directly within the Arabicised-English structure in general, and (4) the "global" force is similar to that found in other x-isations of English. The frame analysis is implemented mostly when simple and complex clauses are involved. 
This paper neither argues for the Arabicisation of English existence directly, nor for its usages in any crucial way. According to the researcher strategy, clauses in Arabicised-English as appears in the usages of the professional Arabs of English associate the various modalities of the clausal interpretation and the morpho-lexicology with a well defined configuration space. This strategy strives to prove fruitful, and this paper is written with this orientation in mind.

\section{Previous Related Works}

Arabicisation of English has not been documented the way Indianisation or Americanisation of English, to mention but two, have been. However, many studies on English as used by educated professional Arab speakers prove beneficial to our study. To exclude those studies that do not relate directly and which involve bilingualism, we are left with some of direct relation.

Bolotin's (1996) study on the Arab speakers' resetting of parameters analyses in depth and their ability to reset parameters show they have full access to UG. They allow both L1 and L2 settings by assuming optional movement hypothesis for English. Mainly, it is the unlearning of an old setting that proves problematic, and not the learning of the new setting.

Demirdache (1991) had analyzed the appositives and dislocation structure of restrictive relatives, and has shown the mechanism of resumptive chains in them. Relative pronouns which occur in the complex structure prove problematic to some speakers of other languages.

Walters' (1996) study on language change in Arabic added to quantitative linguistic literature in that little or no effect is found on patterns of the linguistic variation in aspects of speech where diglossia is found. Examining the specific case of Arabic, Walters (1996) related the speakers "stylistic choices" to the selection of the range of varieties they might command. These varieties are linked in complex ways to patterns of social interactions and are "hyperstyle variables related to diglossia" (p. 191).

The above study conforms to this paper in that it exemplifies the ability among professional Arab speakers of English with an unmarked choice. The positive role of the diglossic situation in Arabic language exhibits variations linguistically and sociolinguistically that is proved in their usage of English (Walters, 1996)

Other related, though not directly, works deal with diglossic and bilingual situations in Arabic Language and in the Arab World. Variable topics are involved in the discussion including lexical borrowings in the Eastern Province of Saudi Arabia, and the Pidginization of the Gulf Arabic. Moreover, borrowing in Arabic American speech is analysed with brilliant contribution and conclusions (see among others Zughoul, 1979; Suleiman, 1985; Smart, 1990; Rouchdy, 1992).

\section{Data and Analysis: Data, Subjects, and Context}

The context of data is from various spoken sources by Arabs from the Middle East, the Gulf, Morocco, and Tunisia, to ensure variability and objectivity. The participants are 22 adults who are all well educated and with a professional knowledge of English. They are all Arabs of equal males and females number. Their professions include: postgraduate students of different specialties that are taught in English, medical doctors, university professors, business men and women, and two students in their final stage of education in a British school.

Data are collected by recording them in writing from various contexts. These involve interviews and chats-shows from Arabic TV channels broadcasted in English, where the interviewees and announcers are usually Arabs who studied Arabic and have a good command of English. Data also involve mobile informal 
text messages, conversations in cafeterias and hallways, and informal instant speeches delivered at schools with no prior preparation. The subjects' age ranges between 20-40 years and were all taught Arabic at schools as well. Total data are 561 sentences (simple and complex).

\section{Analysis and Discussion}

Data are discussed below following classified sub-headings upon their linguistic variations.

\section{Simple and Complex Clauses}

Simple and Complex clauses occur in our data with no significant difference between the subjects' performance and Standard English (Quirk, 2003; Greenbaum \& Quirk, 2000). The following sentences are extracted from the Data (see Examples (1)-(3)):

Example (1) May be he could not tell you.

Example (2) There is no particular people there.

Example (3) Those do nothing.

The above are simple clauses. The usage of initial adverbial phrases may be as in Example (1), and the expletive there mark the variety of Arabicised-English. On the other hand, a resort to simple clauses is the first and predominating choice of users. Arabs do extremely well in using Arabicised English similar to Standard English. However, the clause may be to initiate the sentence is quite common here. Whereas in Standard English the adverb (perhaps) is more likely to occur in a similar context.

But when longer or complex sentences are involved certain linguistic phrases are used as follows (see Example (4)):

Example (4) Usually, our art coming from various places which mostly relate to culture.

Where the initially inserted AdvP (Adverb Phrase) usually is used, the complex clause tends to lack the auxiliary verb (to be). This occurs only occasionally. People are aware of the broken structure that may be created, and their English structure is not usually broken. So, in Example (4), the verb coming is estimated as main by resetting parameters of their first language with full access to UG. This situation may be similar to Arabic long clauses where they depend on LF. This means that in Arabic no movement is required on the surface structure as that of English (Bolotin, 1996, p. 138).

More variations are witnessed in the following usage where the insertion of an auxiliary is made inside the embedded clause (see Example (5)):

Example (5) That's what's I supposed to be.

Verb (to be) is inserted twice: Once is after the demonstrative that, and another time is following the interrogative what, where an overgeneralization occurs.

The following data reveal that there is very little or no difference found between the two varieties of Arabicised and Standard Englishes (see Examples (6)-(8)):

Example (6) They like their culture.

Example (7) You can feel artists are really working from their own cultural background.

Example (8) Art in our country, I would say, is at its golden age.

The simple clauses are Example (6) and Example (8) where the former is remarkably short when compared to the latter. The complex clause is Example (7) above and contains one word adverb-phrase: really, which is the topic of the sub-section below. 
Figure 5 is a visual presentation of the occurrence of both types of clauses, simple and complex, according to our data of the total of 561 clauses:

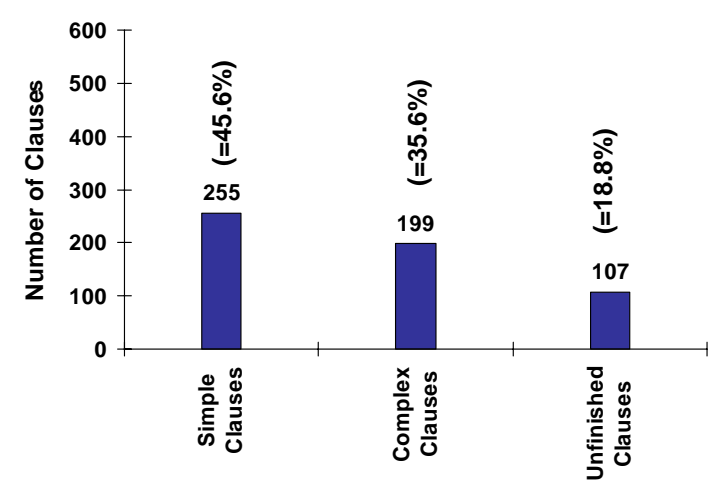

Figure 5. Variations of simple and complex clauses in oral data.

Where in speaking, resetting parameters according to Arabicised-English is $35.6 \%$ of complex clauses which is more challenging than the simple ones. The complex clauses involve longer ideas to reformulate according to English parameters. Simple clauses are the most desirable as they conform over $45 \%$ of the data. The third type (of the unfinished clauses) form $18.8 \%$ as they occasionally penetrate in the verbal conversation. They are immediately compensated by complete clauses.

\section{Free Insertion of Adverbs and Adverbial Phrases}

The occurrence of really in the initial, middle or final position of the sentence is exhibited in a big number of sentences. The following are extractions (see Examples (9)-(11)):

Example (9) What we think about really is to offer good pieces for people.

Example (10) We've just established our art association where there are many artists that are committed and are really busy.

Example (11) Artists can reach anywhere in the world really.

Really appears italicized in the above data. It is the adverbial phrase which enjoys, together with other adverbial phrases, a relatively free mobility around the sentence, i.e., it can occur initially, medially, or finally. However, in Example (10), really is a degree modifier within the adjective phrase really busy.

Examples (12)-(14) exhibit other adverbial phrases of emphasis:

Example (12) Art in our country, I would say, is at its golden age.

Example (13) When I saw your message, you know, I felt ashamed.

Example (14) Actually, I am more than angry.

The italicized phrases/clauses vary in structure such as: the simple clauses: I would say and you know, and the AdvP: Actually in Example (12), Example (13), and Example (14) respectively. They are freely used and are frequently found in our data. More of these adverbials such as anyway, on top of that, and may be are exhibited as follows (see Examples (15)-(18)):

Example (15) My be he could not tell that.

Example (16) Anyway I am sorry to upset you.

Example (17) On top of that, I ran to you as a daughter more than as a student.

Example (18) Really, thank you is not enough. 
Adverbial phrases are the italicized forms as they occur initially in Examples (15)-(18). They are: May be, Anyway, On top of that, and Really. They occur in the beginning to mark topicalization.

However, in Example (17), the difference between English and Arabic is exhibited in the structure. The prepositional phrases as a daughter and more as a student show such difference in English/Arabic parameters. English is specific as having syntactic operations and movement at the surface structure whereas Arabic works at the LF level (Demirdache, 1991; Bolotin, 1996).

Accordingly, the head-noun (you) in Example (17) is the modified NP (Noun Phrase) by the adverbial phrases: as a daughter and as a student, because it directly precedes. But, the speaker refers to the head-noun I which occurs earlier in the sentence, to be the main modified NP.

The expected structure in Standard English is: $I$ ran as a daughter more than as a student to you.

This situation occurs occasionally, and the context takes care of the meaning most of the time.

The frequency of using PPs (Preposition Phrases), AdvPs, and adverbials which occur in the data of 561 clauses are visually presented in Figure 6:

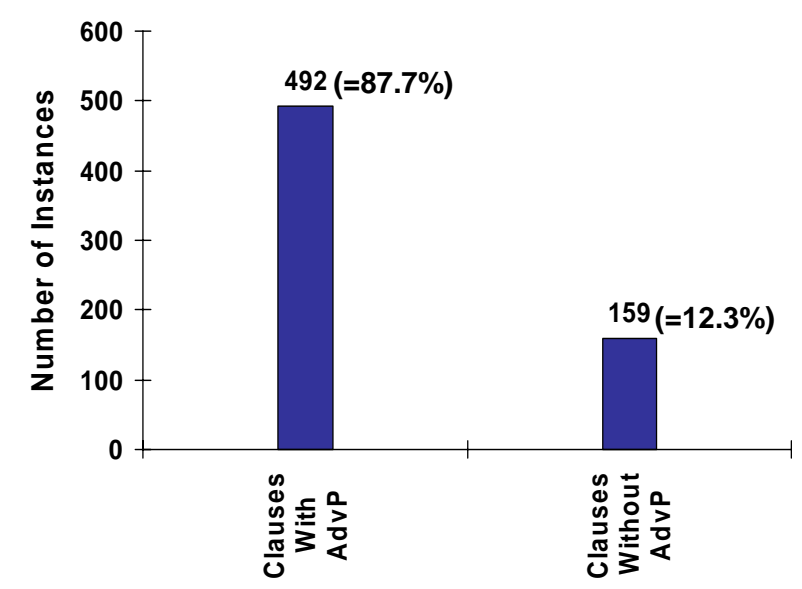

Figure 6. Variations in inserted Adverb and adverbial phrases, and PPs.

\section{The Occurrence of and and very}

The usage of both the adverb-degree modifier very and the coordinating conjunction and mark the variety of Arabicised-English. The degree modifier is generously used in Arabic language and dialects (Al-Shurafa, 2006a, 2006b). The connector and also occurs in a desirable abundance in Arabic as a necessity to complement the structure and to connect the words, phrases, and sentences (Al-Shurafa, 2006c).

The following are examples of very forms (see Examples (19)-(22)):

Example (19) ... very very valuable.

Example (20) ... a very exciting story.

Example (21) ... extremely very low prices.

Example (22) They are very, you know, very happy.

Very appears in italics above. The degree modifier reflects stressing on emotional expressions. This is directly reflected from Arabic language into the variety of the Arabicised-English.

Similar distinct features have been acknowledged in Indianised and other Englishes (Stockwell, 2002, pp. 180-181). Courtesy in Arabic has also been examined (Al-Jehani, 1993, pp. 17-26), in which its direct effect is exhibited in the overall style and structure of Arabicised-English. 
Courtesy can be reflected in the usage of very which appears once (as in Example (20) and Example (21)) or twice (as in Example (19) and Example (22)). The degree modifiers are found to precede already expressive adjectives where courtesy and emphasis of emotions are created. These expressive and emphatic adjectives are (valuable, exciting, and happy) above.

Connectors are freely occurring at times too, as in Example (23):

Example (23) God bless you and thanks.

In Example (23), both emotional and emphatic expressions are coordinated with and. It implies the sense of gratitude and "courtesy" (Al-Jehani, 1993, p. 13).

\section{The Usage of the First Person Singular Pronoun I}

In simple clauses, Arabicised-English is found to be marked by using the reference to the first single person. The following is part of an informal message that was sent through the mobile (see Example (24)):

Example (24) I made you upset.

I felt sad because of my reaction.

$I$ wanted to call and apologise.

was shocked and disappointed.

When $I$ saw your message, $I$ felt ashamed.

I am actually more than grateful.

I do not know what to say.

The above message is one continuous unit which contains eight occurrences of $I$ and one first person possessive pronoun my which can be considered here as a related derivation to $I$. This makes up the total of nine instances of the first person reference. The rate of this usage against the total number of words in this message appears as $43: 9$, which is roughly $29 \%$ of the total message.

The message is also emotional and carries emphatic expressions, as in: actually and more than grateful. This is beside the "expressive" adjectives upset, shocked, disappointed, ashamed, and grateful. The latter has been preceded by the modifying phrase more than. These evidences are interpretations of culture which involve marked “courtesy” (Al-Jehani, 1993, pp. 20-22).

\section{Occurrence of the Expletive It}

In simple and complex clauses, the dummy subject pronoun it is found markedly occurring initially or medially. It is highly desirable to be used in this variety of English, as in the following selected clauses (or parts of the clauses) (see Examples (25)-(29)):

Example (25) It is apparent that...

Example (26) This shows that it is tackling something new.

Example (27) It is also continued to discuss...

Example (28) It also identifies verbal cues.

Example (29) It also involves field work.

The clauses or parts of the clauses above are initiated, except for Example (26) by the usage of $i t$. These are some of many of the total data of 561 clauses. A count is made which revealed that 495 clauses contain the expletive $i$; that is more than $82 \%$. This percentage is considerably high.

Emphasis is also exhibited in the above extracted data. Also in Examples (27)-(29) is used in the sense of 
confirming the already stated facts. A similar manner of emphasis as well as the usage of it reference appears together, as in the following (see Example (30)):

Example (30) It provides as much as possible a more natural spoken setting for authentic data.

Emphasis is conveyed through usages that are in italics above, namely: as much as possible and more. According to Arabic language and culture, this usage is desirable rather than verbose. Moreover, adjectives such as authentic is not adding much to the adjective natural which precedes it. Emphasis is felt necessary and is used in abundance in our data.

\section{Coordinated Parts of Speech, and Modifiers}

These features are exhibited in many of the above extracted data. However, the following are more of the used modified nouns, verbs, adjectives, and adverbs (see Examples (31)-(37))

Example (31) ... have many challenges

Example (32) ... but far more challenges

Example (33) ... mainly an attempt

Example (34) ... significantly influences

Example (35) ... It is of great importance

Example (36) ... appropriately and successfully

Example (37) ... becomes more and more important

The above are seven usages that are selected to provide various occurrences of structural features discussed under this subsection. The following is a classification in order to clarify the structure of Examples (31)-(37) where (a) is added for each of the corresponding structure:

(31) a $\bmod ($ num) $+\mathrm{N}$

(32) a $\bmod ($ intensifier) $+\bmod ($ deg) Comparative $+\mathrm{N}$

(33) a $\quad$ AdvP+ NP

(34) a $\quad$ AdvP+ V

(35) a AdjP+ N

(36) a $\quad \operatorname{AdvP}($ coord) AdvP

(37) a $\bmod (\mathrm{deg})$ (coord) mod (deg)+ Adj

The above sentences occur together in one paragraph in the data. Almost each sentence contains modification and/or coordination. The feature of coordinated or "sacked" adjectives and adverbs are desirable in Arabic language and dialects (Al-Shurafa, 2006a, 2006c).

Speakers do well on the whole, even though they seem to assume at times that Arabic parameters also apply to their performing of English.

\section{Conclusions and Recommendations}

The following section involves the main conclusion of this study. It summarizes the main variations that characterize Arabicised-English which have been discussed in details during the text. Thereafter, recommendations for future work in this line are suggested.

\section{Conclusions}

Universal education involving English within each of the Arab countries and families has given rise to new kinds of social stratification (as it does in every society) that embarks on such a path. Arabicisation of 
English is the most obvious path which it depends on face-to-face interaction (Fishman, 2001; Fishman et al., 1986; Walters, 1996; Crystal, 2003, 2004).

It has been clear from the discussion in the paper that similar "global" force is found in the Arabicisation of English to those of the Indianisation of English in terms of polite, conservative, formal, and even emphatic style of courtesy.

It has been exhibited that there is a frequent insertion of certain phrases such as you know, I mean; adverbs and adverbial phrases like usually, really, and actually; the higher desirability of using simple clauses to complex ones; the marked occurrence of very and the connector and; the predominating usage of $I t$; and the coordination of various parts of speech, particularly descriptive adjectives which are found in coordination together with the degree modifier as (... more and more).

All the above go in congruent with the selected theoretical framework of Chomsky, where in speaking, the resetting of parameters according to Arabicised-English shows some effect or sometimes overlapping of Arabic as L1 over the variety of English used as L2.

However, the generous occurrence of adverbial phrases and the like confirms the seeking by the user to insure clarity, politeness, and even courtesy at times. Repeated phrases and synonymous adjectives of emphasis at the phrasal level are also found in the variety of Arabicised-English.

\section{Recommendations}

For future research, Arabicisation of English requires a number of topics to cover. The basic topics for such study are summarized in the following points:

Research requires to focus separately on written and spoken data for independent searching on Arabicised-English. As for this study, data have been collected from informal contexts and reached unprecedented number of conclusions. For more conclusions, this is expected to expose the researcher to documented data that would yield brilliant results concerning parameters and linguistic variations.

Because of the multi-lingual context of Arabic speakers, they are advantaged with their intellectual development. Accordingly, informants with many friends from various linguistic background may expose the researcher to a number of original linguistic variations and facts of Arabicised-English.

The question of the change of parameters in speaking another language by Arabs and whether these parameters are of similar settings to those of Arabicised-English or different is worthwhile searching for.

The above are few suggestions for some areas that are expected to clarify valuable linguistic features. These questions remain open-ended until documentation of the Arabicisation of English occupies a solid position as is the case with other languages within the $\mathrm{x}$-isation theory of English.

\section{References}

Alim, H. S. (2004). Hearing what's not said and missing what is: Black language in white public space. In S. Keisling, \& C. Paulston (Eds.), Discourse and intercultural communication: The essential readings. Malden, M.A.: Blackwell Publishers.

Al-Jehani, N. J. (1993). Elaborate courtesy in western Arabia. Journal of King Abdul-Aziz University, 6, 17-26.

Al-Shurafa, N. S. (2006a). Word order and morphosyntactic features of adverbs and adverbials in Arabic. Journal of Arts and Humanities, 18(2), 85-100.

Al-Shurafa, N. S. (2006b). Syntactic analysis of marked equative sentences in Arabic: Minimality program. Arabic Journal for the Humanities, 24(94), 241-256.

Al-Shurafa, N. S. (2006c). Syntactic ordering and semantic aspects of adjectives and adjectival phrases in Arabic. University of Sharja Journal (A Refereed Scientific Periodical), 3(1), 1-21.

Bhatt, R. M. (2006). Optimal expressions in Indian English. Cambridge Journals, English Languages and Linguistics, 4, 69-95. 
Bolotin, N. (1996). Arabic speakers resetting of parameters. In M. Eid (Ed.), Perspectives of Arabic linguistics VIII (pp. 135-155). Amsterdam: John Benjamins Publishing Company.

Chomsky, N. (1995). The minimalist program. Cambridge, M.A.: MIT Press.

Crewe, W. (1977). The English language in Singapore. Singapore: Eastern University Press.

Crystal, D. (2003). English as a global language (3rd ed.). Cambridge: Cambridge University Press.

Crystal, D. (2004). The language revolution. Cambridge: Polity Press.

Demirdache, H. (1991). Resumptive chains in restrictive relatives, appositive and dislocation structures (Ph.D. dissertation). Cambridge, M.A.: MIT Press.

Fishman, J. A. (Ed.). (2001). Can threatened language be used? Reversing language shift revisited: 21st century perspective. Cleverdon: Multilingual Matters.

Fishman, J. A., Tabourel-Keller, A., Clyne, M., Krishnamurti, B., \& Abdulaziz, M. (Eds.). (1986). The Furgusonian impact. Berlin: Mouton de Gruyter.

Foley, J. (Ed.). (1988). New Englishes: The case of Singapore. Singapore: Singapore University Press.

Green, L. J. (2002). African American English: A linguistic introduction. Cambridge: Cambridge University Press.

Greenbaum, S., \& Quirk, R. (2000). A student's grammar of English language. London: Longman.

Greenberg, R. D. (2002). Language and the identity in Balkan: Serbo-Croatian and its disintegration. Oxford: Oxford University Press.

Hickey, R. (2004). Legacies of colonial English. Cambridge: Cambridge University Press.

Kachru, B. B. (1988). The alchemy of English: The spread, functions and models of non-native Englishes. Oxford: Pergamon.

Kaplan, R. B. (1966). Cultural thought patterns in intercultural education. Language Learning, 16, 1-20.

Lilles, J. (2000). The myth of Canadian English. English Today, 16(2), 13-19.

Maurice, J., \& Morris, M. (2004). Languages in globalising world. Cambridge: Cambridge University Press.

Mazzon, G. (1993). English in Malta. English World Wide, 14(2), 171-208.

Melchers, G. (2003). World Englishes. Oxford: Oxford University Press.

Mesthrie, R., \& Bhatt, R. M. (2008). World Englishes: An introduction to new linguistic varieties. Cambridge: Cambridge University Press.

Mohammad, M. A. (2000). Word order, agreement and pronominalization in standard and Palestinian Arabic. Amsterdam: John Benjamins Publishing Company.

Quirk, R. (2003). A comprehensive grammar of the English language. London: Longman.

Raley, R. (1999). On global English and transmutation of post colonial studies into literature of English. Diaspora: A Journal of Transnational Studies, 8(1), 51-80.

Rouchdy, A. (1992). Borrowing in Arabic American speech. In A. Rouchdy (Ed.), The Arabic language in America (pp. 36-49). Detroit: Wayne State University Press.

Shlonsky, U. (1997). Clause structure and word order in Hebrew and Arabic: An essay in comparative Semitic syntax. Oxford: Oxford University Press.

Smart, J. R. (1990). Pidginization of gulf Arabic: A first report. Anthropological Linguistics, 32(1-2), 83-119.

Stockwell, P. (2002). Sociolinguistics: A resource book for students. London: Rutledge.

Suleiman, S. M. (1985). Jordanian Arabic between diglossia and bilingualism linguistic analysis. Amsterdam: John Benjamins Publishing Company.

Trudgill, P. (1999). Standard English: What it isn’t. Paper presented in Poetic and Linguistics Association Conference, University of Bern, Australia.

Walters, K. (1996). Diglossia, linguistic variation and language change in Arabic. In M. Eid (Ed.), Perspectives of Arabic linguistics VIII (pp. 157-197). Amsterdam: John Benjamins Publishing Company.

Warsi, M. J. (2004). Indianization of English media in India: An overview. In M. S. Thirumalai, B. Mallikarjun, S. Mohanlal, \& B. A. Sharada (Eds.), Language in India (Vol. 4(8)). California: University of Berkerly Center for South Asia Studies.

Wright, S. (2004). Language policy and language planning: From nationalism to globalisation. New York: Palgrave Macmillan.

Zughoul, M. R. (1979). Lexical interference of English in eastern province Saudi Arabia. Anthropological Linguistics, 20(5), 214-225. 